\title{
Discussion of University Performance-Related Pay Incentive Mechanism Based on the Analysis of Gini Coefficient
}

\author{
Ying ZHANG $^{1, a,{ }^{*},}$ Ming-Ming HUANG ${ }^{2, b}$ \\ ${ }^{1}$ Room 108, College of life science and technology, Jinan University, 601 West Huangpu Avenue, \\ Guangzhou, China \\ ${ }^{2}$ School of Chemical Engineering and Technology, Sun Yat-sen University Zhuhai Campus, \\ Tangjiawan, Zhuhai, China \\ atzhangying@jnu.edu.cn, bhmm89@mail.sysu.edu.cn
}

Keywords: Gini Coefficient, Performance-related pay, Incentive mechanism, University.

\begin{abstract}
Auniversity performance-related pay analysis using Gini Coefficient, through the questionnaire survey data to calculate a new performance-related pay university Gini Coefficient of 0.33, the corollary of Gini Coefficient $0.33-0.4$ is the reasonable value of the university performance-related pay. The teaching and research staff with higher performance-related pay Gini Coefficient are fully competitive,the incentive mechanism has achieved good results. The laboratory staff and administrative staff with lower performance-related pay Gini Coefficient aretoo average income distribution, lack of motivation, the incentive mechanism should be further optimized and improved.
\end{abstract}

\section{The Current University Performance-Related Pay Salary System}

Since 2006, China has been reforming the salary system of public institutions, setting up a system of income distribution that reflects the performance and the management of grading and classification. The salary is composed of basic pay, performance-related pay and allowance. Performance-related pay mainly reflects the staff performance and contribution. The public institutions are allocated in accordance with the standardized procedures and requirements within the total amount of the approved performance-related pay.

The objects of university performance-related pay are respectively professional and technical positions, management positions and work skills positions. Each level and correspond to different salary levels for different positions. Faculty and staff can gradually increase their own income by promotion every year through improve work performance and contribution, which increased their enthusiasm, but also conducive to achieving the internal equity in the distribution of university[1].

\section{Analysis of Gini Coefficient of University Performance-Related Pay and Incentive Mechanism Evaluation Tool:Gini Coefficient}

Table 1 Gini Coefficient of different values represent the meaning

\begin{tabular}{|l|l|}
\hline Gini Coefficient & Meaning \\
\hline \multirow{2}{*}{ less than 0.2} & Absolutely average or too fair \\
\cline { 2 - 2 } & (lack of social motivation) \\
\hline $0.2-0.3$ & Comparative average \\
\hline $0.3-0.4$ & Relatively reasonable \\
\hline 0.4 & International warning line \\
\hline $0.4-0.5$ & Large gap(social instability) \\
\hline above 0.5 & Disparities \\
\hline
\end{tabular}

The Gini Coefficient is an important index for analyzing the current situation of income 
distribution among domestic residents in the world. It is also an important index for measuring the income distribution fairness of people in the field of economics. The smaller the Gene coefficient, the higher the level of fairness, the higher the Gene coefficient and the lower the level of fairness(is shown in Table 1).

The Gini Coefficient has advantages over other measurement tools and can accurately reflect the distributional fairness in the fairness index measurement as the most important tool for fairness index measurement [2]. In this paper, the Gini Coefficient of the selected evaluation indicators are calculated using Excel 2007 software to completed [3].

\section{Sample Selection: Calculation of Performance-Related PayGini Coefficient of a College in a University in Guangdong}

This article chooses a university in Guangdong as a research sample, and the survey object is 274 faculty members in acollege of the university. Since 2011, the university implemented the performance-related payreform, this paper selects the 2013 faculty income distribution analysis. The university can be divided into three series of staff: teaching and research staff, administrative staff and laboratory staff. The personal total income of this university composited of basic pay and performance-related pay, performance-related pay which accounts for about one-third of the total income.

Enter the personal income of the faculty and staff into Excel 2007 by using the formula "= 1- ( 2 * SUM (B1: BX) - BX) / (X * BX)" (where $\mathrm{X}$ is the number of people in column A by input income from less to more, $B$ as the sum of income) [3] in Excel 2007 run calculated that: the total income Gini Coefficient of faculty and staff is 0.229 , the performance-related payGini Coefficient of faculty and staff is 0.418, the performance-related pay GiniCoefficient of teaching and research staffis 0.404 , the performance-related pay Gini Coefficient of administrative staffis 0.122, the performance-related payGini Coefficient of laboratory staffis0.119(is shown in Table 2).

Table 2 The income Gini Coefficient of different series in the university

\begin{tabular}{|l|l|}
\hline Category & Gini Coefficient \\
\hline Total income & 0.229 \\
\hline Whole faculty and staff Performance-related pay & 0.418 \\
\hline Teaching and research staff performance-related pay & 0.404 \\
\hline Administrative staff performance-related pay & 0.122 \\
\hline Laboratory staff performance-related pay & 0.119 \\
\hline
\end{tabular}

From the analysis of results, the performance-related pay Gini Coefficient of administrative staff, laboratory staffis below 0.2, the basic pay Gini Coefficient of the whole faculty staff of college is below 0.2, which belongs to the distribution is too average. The total income Gini Coefficient is between 0.2-0.3, which is relatively average. The performance-related pay Gini Coefficient of the whole faculty staff of college and teaching and research staff is over the warning line of 0.4 , which is still a relatively reasonable stage, but the gap has widened.

\section{Questionnaire Statistical Analysis}

In order to improve and understand the incentive mechanism for performance-related pay distribution, a questionnaire was sent to faculty and staff of the college to understand the expectations of each series on their respective income. The survey involves a wide range of coverage and the results have a certain degree of universality and representativeness. This paper summarizes and analyzes the data in the questionnaire.

The income expectation is higher than the actual income by the statistical questionnaire analysis(is shown in Table 3). The three series showed great differences in their own expectations: the administrative staff only increased by $5 \%$, the teaching and research staff increased by $18 \%$, and the laboratory staff increased by $38 \%$. 
Table 3 Questionnaire comparison of expectations

\begin{tabular}{|l|l|l|}
\hline Category & $\begin{array}{l}\text { The expectation } \\
\text { of the survey } \\
\text { compare to the } \\
\text { actual income }\end{array}$ & $\begin{array}{l}\text { The expectations of the } \\
\text { survey of the respective } \\
\text { series compare to the } \\
\text { actual income }\end{array}$ \\
\hline Total income & $30 \%$ & - \\
\hline $\begin{array}{l}\text { Whole faculty and staff } \\
\text { performance-related pay }\end{array}$ & $32 \%$ & - \\
\hline $\begin{array}{l}\text { Teaching and research staff } \\
\text { performance-related pay }\end{array}$ & $25 \%$ & $18 \%$ \\
\hline Administrative staff performance-related pay & $33 \%$ & $5 \%$ \\
\hline Laboratory staff performance-related pay & $38 \%$ & $43 \%$ \\
\hline
\end{tabular}

\section{Incentive Mechanism Analysis Based on Gini Coefficient}

The expected income of teaching and research staff is $18 \%$ higher than its actual income. Its performance-related payGini Coefficient reaches 0.404, which just exceeds the warning line of 0.4, indicating that the income distribution is at a reasonable level and full competition, and the incentive mechanism is relatively perfect. In this series, better results have been achieved, expectations of their own income expectations have increased and at a reasonable level.

Although the administrative staff has an expected 33\% income increase in the questionnaires, it has the lowest expectation of its own income among the three series, only increasing by $5 \%$. Its performance-related payGini Coefficientis only 0.122, indicating a serious lack of motivation problem. This shows that the desire of self-realization in administrative staff and motivation of incentive mechanism are all seriously insufficient.

Laboratory staff of their own income expectations is the highest of the three series, $43 \%$ higher than their own, but the laboratory staff performance-related pay is the lowest of the three series. The performance-related pay only accounts for less than 1/4 of the total income of the laboratory staff, plus the excessively low performance-related pay Gini Coefficient 0.119 , resulting in a serious lack of motivation. The laboratorystaff most need to reinforce the incentive function and increase the incentive mechanism for their work, in order to meet the need of realizing self-worth.

\section{The Reasonable Salary of Gini Coefficient of College Performance Salary}

The Gini Coefficient is an important index for analyzing the current situation of income distribution among domestic residents in the world. It is also an important index for measuring the income distribution fairness of people in the field of economics. However, university is a closed small group in society. The society's understanding of the Gini Coefficient interval value is only for reference. In this paper, the rationality of the income distribution in university is monitored through the Gini Coefficient. Therefore, it is necessary to set a reference reasonable value for university.

Hu Zuguang derives the Gini Coefficient 0.33 by mathematics as the theoretical best value [4].RenYouzhou measured in a university post allowance Gini Coefficient of 0.35 , that it is consistent with the characteristics of university salary system design [5]. Jiang Changfu calculated post allowance Gini Coefficient of 0.40557 in a university, calculated by comparison, that the Gini Coefficient of the distribution slightly larger gap [6].Cao Zhiwen analysis of a university's performance-related payGini Coefficient of 0.3940, that the distribution gap has driven, is to reflect the performance of the post, the actual performance and contribution of income distribution [1]. LvLijiang calculated Zhejiang University post allowance Gini Coefficient of 0.4 that has reached the distribution gap.

According to the data of the questionnaires, the Gini Coefficient of the new performance-related pay is reduced to 0.330 . Performance-related pay structure at the highest level from the teaching 
and research staff, low-level from the administrative staff and laboratory staff, the highest and lowest gap of up to 10 times, the previous analysis of the three series of incentive mechanism differences is the main reason for the gap. Therefore, the relative increase in the questionnaire of administrative staff, laboratory staff of income(is shown in Table 3)reduce the gap in the income system, so that the performance-related pay fell to 0.3-0.4 Gini Coefficient.

According to Gini Coefficient reasoning and calculus theory, the Gini Coefficient has a positive correlation with each level of range, the larger the level difference, the higher the Gini Coefficient; the Gini Coefficient and the number of people of each level has a negative correlation, the more the number of people, the lower the Gini Coefficient. University belongs to a small group with relatively high level of regional economic development in society. There is not much difference between population level and cultural level in the population. Therefore, the Gini Coefficient in university will not significantly exceed the warning line of 0.4. Therefore, I think that the reasonable value of performance-related pay Gini Coefficient in university is between 0.33-0.4, not only ensures the basic interests of the faculty and staff, but also makes the series in a state of reasonable competition.

\section{Reflection on Performance-Related Pay Incentive Mechanism in University}

In this paper, the Gini Coefficient of performance-related pay is used to obtain the fairness and internal competition of university's income distribution. The author investigates the incentive mechanism and self-cognitive value of each group's expectation of income, and can understand the problems of incentive mechanism in the income distribution system. In this regard made three suggestions:

\section{Promote the Reform ofPerformance-Related Pay Distribution System in University}

Combining with the reform plan for the income distribution system of public institutions since 2006, guided by scientific theories, further deepening the reform goal of performance-related pay in university,reflected the principle of giving priority to fairness and efficiency and ensured a steady and sustained increase of faculty and staff's income, taking into account the incentive mechanism of various series of personnel.In the reform, we need to constantly adjust and change [7]. Universityneed to adjust and optimize the incentive mechanism according to the actual situation.

\section{Implementation of a Variety of Incentives Mechanism for Each Series}

Performance-related pay is one of the most important incentives in the incentive mechanism, but at the same time, it is necessary to implement multiple incentives, which include emotional stimulation, training and development of opportunity incentives, honor and promotion incentives. The faculty and staff in university have non-material characteristics such as high-level and spiritual-oriented. In formulating the incentive mechanism, we should respect the cultural ecology of the university, meet the spiritual needs with the flexible encouragement mechanism, and strengthen the non-material, especially the spiritual and cultural motivation of faculty and staff in university.

Targeted incentive measures are implemented for different series of university staff, such as optimizing the teaching methods of the laboratory staff and the continuous development of the incentive mechanism, setting up key technical positions, setting the titles of senior professors and directors of experimental techniques, etc., paying attention to the training of the administrative staff and formulating the appropriate Continuing Education Model and career planning, the university's work objectives and personal development goals together to enhance the work of identity and sense of accomplishment. Implementation of 360-degree feedback and other multiple evaluation [8], fully mobilize the enthusiasm of administrative staff.

\section{Guide Faculty and Staff to Establish the Values of Scientific Development}

Universities are social institutions that teach and educate people. They should be built as a culture-led ecological environment and guide faculty and staff to establish values based on the 
scientific spirit and guided by the humanistic spirit. Universities should respect the values, interests and contributions of faculty and staff and inspire their sense of mission and responsibility by creating an atmosphere of the environment and a reasonable incentive strategy.

\section{References}

[1] Cao Zhiwen,NiuXiaoye,QuJingshan.An Empirical Analysis of University Income Distribution Based on Post Performance-Related Pay System [J]. FRIENDS OF ACCOUNTING,2013(4):108-111.(In Chinese)

[2] Yu Dengke, Chen Hua, Lang Yifu.Comparison of Gene Coefficient and Entropy in the Measurement of Fair Index [J].STATISTICS \& DECISION,2013(3):95-96.(In Chinese)

[3] Gao Ji. Calculation and Study of Gini Coefficient under EXCEL [J].ZHEJIANG STATISTICS,2008(6):41-43.(In Chinese)

[4] $\mathrm{Hu}$ Zuguang. A Study of the Best Theoretical Value of GiniCoefficientand Its Concise Calculation Formula [J].ECONOMIC RESEARCH JOURNAL,2004(9):60-69.(In Chinese)

[5] RenYouzhou, Liang Fangyong, Yang Wanwen. A new exploration of Gini Coefficient of institutions of higher learning [J].JOURNAL OF HUAZHONG NORMAL UNIVERSITY, 2013(3):446-449.(In Chinese)

[6] J IANG Chang- fu. A Study of the justness of allowance system in institutions of higher learning [J]. JOURNAL OF HUAINAN TEACHERS COLLEGE,2007(5):69-71.(In Chinese)

[7] LI Xiao-ming, LU Wu-xia.A Way of System to Construct the Teacher-Incentive Mechanism [J]. Theory and Practice of Education,2010(2):37-39.(In Chinese)

[8]Han Bochang, Shang Zanti.Comparison and Selection of Human Resources Performance Evaluation Methods [J].SCIENCE AND TECHNOLOGY MANAGEMENT RESEARCH,2002(6):76-79.(In Chinese) 